\title{
Standardised functional assessment in long-term care for older people: perspective of Finnish care workers
}

\section{Vilhelmiina Lehto-Niskala*}

Faculty of Social Sciences (Health Sciences) and Gerontology Research Center Tampere University, Finland

Email: Vilhelmiina.lehto-niskala@tuni.fi

${ }^{*}$ corresponding author

\section{Outi Jolanki}

Faculty of Social Sciences (Health Sciences)

Tampere University, Finland

Department of Social Sciences and Philosophy and Gerontology Research Center

University of Jyväskylä, Finland

Email: outi.jolanki@tuni.fi

\section{Jaakko Valvanne}

Faculty of Medicine and Life Sciences and Gerontology Research Center

Tampere University, Finland

jaakko.valvanne@tuni.fi

\section{Marja Jylhä}

Faculty of Social Sciences (Health Sciences) and Gerontology Research Center Tampere University, Finland

Email: marja.jylha@tuni.fi 


\begin{abstract}
Objective measures and documentation are increasingly used in the care for older people to promote efficiency and productivity. A standardised assessment of functional capacity is one such measure. In this study, we examined the meanings given to standardised functional assessment by care workers who provide long-term care for older people. Gathered from eight Finnish long-term care facilities, the data consisted of one-on-one interviews with practical and registered nurses $(n=24)$. In the data analysis, we employed the discursive approach. We identified three discourses in the care workers' talks that differed in the meaning given to standardised functional assessment in the process of care: part of the bureaucracy, a missed opportunity and a threat to person-centred care. Care workers described these assessments as constituting a routine part of their job but expressed uncertainty about their role and the practical benefits in actual care work. They even called into question these assessments' relevance to quality care delivery. To be a meaningful part of care practice, it is essential that there be a shared understanding of the rationale behind functional assessments in the care organisation and that care workers themselves can see the outcomes of these assessments in their daily work.
\end{abstract}

Keywords: functional assessment, long-term care, policy, aged, nursing care, residential facilities

\title{
Introduction
}

Over the past 10-15 years, the drive to increase efficiency and productivity has brought major organisational changes in health and social care in the Nordic countries, with wideranging effects on daily care work, especially on the care for older people (Anttonen \& Häikiö, 2011; Dahl, 2009; Nilsson et al., 2018; Strandell, 2019; Szebehely \& Meagher, 2018; Trydegård, 2012; Vabø, 2006). These changes can be viewed as part of the new public management (NPM) doctrine, which emphasises the importance of productivity, standardisation and measured outcomes in the public sector (Adcroft \& Willis, 2005; Dahl, 2009; Trydegård, 2012). Vabø (2006) states that for care workers, this shift in emphasis has meant spending more time on using standardised documentation and quality measurement tools instead of working beside older persons. It has also been suggested that with these changes in the organisation and management of care, care 
workers now have less autonomy and flexibility on the job (Dahl, 2009; Henriksson \& Wrede, 2008; Trydegård, 2012). At the same time, the idea of person-centred care has affirmed its place in the care for older people (Finlex, 2012; Norwegian Ministry of Health and Care Services, 2016). This concept highlights older persons' self- determination and partnership with caregivers (McCormack, 2003; McCormack et al., 2012; McGilton et al., 2012). Measuring performance and outcomes are central to the NPM doctrine (Adcroft \& Willis, 2005). We maintain that in the context of older people's care, an integral part of the ongoing drive towards greater efficiency is the increased use of assessment tools. Among the various instruments that are used (Stoop et al., 2019), many include assessments of functional capacity. The development of standardised functional assessment indexes originated from the need to evaluate impairment caused by disease (Guralnik \& Lacroix, 1992; Katz et al., 1970; Mahoney \& Barthel, 1965). These indexes have been used to predict adverse outcomes and a further decline in functioning, evaluate quality of life in older populations (Guralnik \& Lacroix, 1992), facilitate communication (Lawton, 1971) and assess rehabilitation (Lawton, 1971; Mahoney \& Barthel, 1965). Some functional assessment instruments are research-specific, while others are used for practical care situations (Guralnik \& Ferrucci, 2003; Guralnik \& Lacroix, 1992). Today, the assessment of functioning among older persons is an essential part of determining their service needs and evaluating the quality and efficiency of care.

The Resident Assessment Instrument (RAI) is one of the best-known comprehensive assessment tools for long-term care (LTC) and includes a component for functional assessment (Finne-Soveri et al., 2010; Hawes et al., 1997; Zimmerman et al., 1995). The RAI is intended to improve the quality of care and to develop individualised care plans, but it can also be used at the management level for benchmarking purposes (Finne-Soveri et al., 2010) and even to determine resource utilisation and care home payments (Hawes et al., 1997). While nursing home staff members have mainly taken a positive view on the RAI (Hansebo et al., 1998; Jogerst et al., 2002; Parmelee et al., 2009), the assessment process has been regarded as time-consuming (Armstrong et al., 2016; Hansebo et al., 1998; Jogerst et al., 2002; Parmelee et al., 2009) and not reflective of the actual care or the assessed person (Armstrong et al., 2016; Hansebo et al., 1998; Parmelee et al., 2009). Armstrong et al. (2016) have argued that the RAl represents a 
new way of governing with market-based principles and is oriented more towards medical conditions and less towards caring and social relationships.

This study was conducted in Finland where LTC for older people consists of nursing home care, assisted living with 24-hour care, and LTC wards in hospitals and in health care centres (Johansson, 2010). The use of LTC increases with age, especially in the last years of life (Forma et al., 2007, 2017). As in other Nordic countries, Finnish policies are aimed at reducing LTC and allowing older people to live at home for as long as possible (Ministry of Social Affairs and Health, 2013). As a result, most older people have significant care needs by the time they move into an LTC facility. In Finland, the responsibility for the organisation of LTC for older people and the management of access to care rests with municipalities (Finlex, 2012), but practical care provision is often outsourced to private organisations. Private care services purchased and paid directly by customers are marginal.

Standardised structured multi-dimensional assessments, including assessments of functional capacity (Stoop et al., 2019), are routinely conducted for admission to home care or LTC in Finland. These assessments are also used on a regular basis during care to update recipients' care plans and to determine care needs (Finlex, 2012; Ministry of Social Affairs and Health, 2017; Voutilainen \& Vaarama, 2005). Currently, one of the most common instruments in Finnish LTC is RAI, which was first used in the country in the early 2000s (Finne-Soveri et al., 2010). Since then, objective measures and increased documentation, both closely linked to NPM principles, have become regular features in the care for older people. The assessments are mainly performed by care professionals, yet to our knowledge, no research has been conducted concerning their views on the role and the use of these assessments. Previous research has reported the validity and reliability of functional assessment instruments (Hawes et al., 1995; Hirdes et al., 2008; Mor et al., 2003; Richards et al., 2000; Sainsbury et al., 2005), but only a few studies have explored care professionals' views on these assessments' benefits and feasibility. There is a lack of knowledge on whether care workers who conduct the assessments and are mainly responsible for the caring process consider these assessments useful in their everyday work. In fact, little is known about the role of these assessments in the organisation and practice of care in general. To gain a deeper 
understanding of care workers' views, we interviewed them for this study to explore the meanings they assigned to standardised functional assessments.

\section{Methods}

\section{Design}

We chose a qualitative method of data collection by conducting face-to-face interviews and applying a discursive approach to data analysis. Standardised assessment tools are used in several countries around the world as ways of improving the efficiency and arguably, the quality of care for older people. We were interested to find out whether the care workers using these tools in their daily work shared this view or whether they had other complementary or contrasting opinions. The discursive approach is particularly useful in data-driven explorative research whose aim is to unravel the meanings of a given topic, without any predefined assumptions on what these meanings might be (Wiggins \& Potter, 2017). Our analysis focused on how the care workers' talks portrayed standard functional assessment as part of their job. Our approach shares Phelan's (2011) advocated idea that studying care workers' talks about their daily work makes it possible to unravel taken-for-granted views about care practices and opens new and different perspectives on care work and daily life in LTC. Additionally, our premise is that care professionals' understanding and way of talking about their work both reflect and affect practices in the care for older adults (Phelan, 2011).

\section{Participants}

Using purposive sampling, we gathered the data in 2016 from eight LTC facilities for older persons in two municipalities in southern Finland. We wanted to collect data from both institutional care (nursing homes and long-term hospital wards) and assisted living settings. Four out of the eight participating facilities provided institutional care and four provided assisted living with 24-hour care. Two of them were public and six were private facilities, but all were service providers for municipalities. The facilities are described in more detail elsewhere (Lehto et al., 2017).

The manager of each care facility was asked to nominate three care workers to participate in the study. The care workers had to be registered or practical nurses, as 
both usually participate in care work in Finland. Practical nurses are health and social care professionals with a protected occupational title and three-year training. Practical nurses provide, plan and assess care (Finnish National Agency for Education, 2017). The responsibility for nursing and medication management in LTC facilities rests mainly with registered nurses, who also participate in the personal care for residents alongside practical nurses. Despite the different roles and duties of registered nurses and practical nurses, both conduct functional assessment as a regular part of their jobs, so the two groups were not separated for the analysis. In total, 24 nurses were interviewed (Table 1). Before the interview, the participants were informed about their voluntary participation and their right to withdraw their consent at any time.

\section{Data collection}

The first author conducted semi-structured one-on-one interviews in Finnish with the care workers in the LTC facilities. All interviewees were informed about the study's main goals and that the interviewer was a researcher and a registered nurse with LTC experience. An interview guide focusing on functioning and rehabilitation was used but not rigidly followed; the purpose was to allow the interviewees to concentrate on the themes that they thought were most important. Functional assessment was addressed in connection with the item that asked whether the interviewee evaluated the functioning of residents. If the interviewee mentioned a specific instrument such as RAI, the interviewer would follow up and probe more deeply. These questions included how, why and for whom the assessment was conducted. Lasting from less than half an hour to an hour, the interviews were audio recorded and transcribed verbatim. The transcribed interviews totalled 63,680 words. 
Table 1. Research data: 24 semi-structured interviews

\begin{tabular}{|c|c|c|c|c|c|}
\hline Name & Type of facility & Occupation & Gender & $\begin{array}{l}\text { Years in current } \\
\text { position }\end{array}$ & Age (years) \\
\hline Joanna & $\mathrm{NH}$ & $\mathrm{RN}$ & Female & $1-5$ & $\mathrm{n} / \mathrm{a}$ \\
\hline Emma & $\mathrm{NH}$ & $\mathrm{PN}$ & Female & $1-5$ & 29 \\
\hline Eeva & $\mathrm{NH}$ & $\mathrm{PN}$ & Female & $1-5$ & 24 \\
\hline Elsi & $\mathrm{NH}$ & $\mathrm{PN}$ & Female & $>5$ & $\mathrm{n} / \mathrm{a}$ \\
\hline Juulia & $\mathrm{NH}$ & $\mathrm{RN}$ & Female & $1-5$ & 59 \\
\hline Irene & NH & $\mathrm{PN}$ & Female & $>5$ & 50 \\
\hline Amanda & $\mathrm{AL}$ & $\mathrm{RN}$ & Female & $1-5$ & 28 \\
\hline Moona & $\mathrm{AL}$ & PN & Female & $>5$ & 56 \\
\hline Tiina & $\mathrm{AL}$ & $\mathrm{PN}$ & Female & $>5$ & 44 \\
\hline Paula & $\mathrm{AL}$ & $\mathrm{PN}$ & Female & $1-5$ & 26 \\
\hline Elisa & $\mathrm{AL}$ & $\mathrm{PN}$ & Female & $>5$ & $\mathrm{n} / \mathrm{a}$ \\
\hline Miia & $\mathrm{AL}$ & PN & Female & $1-5$ & 41 \\
\hline Veera & LTC ward & $\mathrm{PN}$ & Female & $1-5$ & 60 \\
\hline Helena & LTC ward & $\mathrm{PN}$ & Female & $>5$ & 64 \\
\hline Maija & LTC ward & PN & Female & $>5$ & 52 \\
\hline Olivia & LTC ward & $\mathrm{RN}$ & Female & $>5$ & 55 \\
\hline Birgitta & LTC ward & $\mathrm{PN}$ & Female & $>5$ & 59 \\
\hline Leila & LTC ward & $\mathrm{PN}$ & Female & $>5$ & 25 \\
\hline Josefiina & $\mathrm{AL}$ & $\mathrm{PN}$ & Female & $<1$ & 24 \\
\hline Meri & $\mathrm{AL}$ & PN & Female & $<1$ & 24 \\
\hline Miranda & $\mathrm{AL}$ & $\mathrm{PN}$ & Female & $1-5$ & 40 \\
\hline Tuomas & $\mathrm{AL}$ & $\mathrm{PN}$ & Male & $1-5$ & 32 \\
\hline Kaarina & $\mathrm{AL}$ & $\mathrm{PN}$ & Female & $1-5$ & 48 \\
\hline Eveliina & $\mathrm{AL}$ & $\mathrm{RN}$ & Female & $1-5$ & 34 \\
\hline
\end{tabular}

$\mathrm{RN}=$ registered nurse, $\mathrm{PN}=$ practical nurse, $\mathrm{NH}=$ nursing home, $\mathrm{LTC}=$ long-term care, $\mathrm{AL}=$ assisted living with 24 -hour care, $\mathrm{n} / \mathrm{a}=$ not available 


\section{Data analysis}

The transcribed interviews were read through several times to gain an in-depth knowledge of the data. The first author conducted the coding process for the analysis, which involved identifying and marking the interview excerpts that somehow referred to functional assessment and then coding these marked excerpts. At this point, a code could consist of a single word or sentence, but as the analysis proceeded, the codes became more elaborate and comprised several sentences or turns of talk. After the preliminary coding, the data were re-read several times to map differences and similarities in the interview talks. The aim of the process was to identify variations in the talks, that is, the different ways of talking about the meaning of functional assessment in care work.

We discussed the findings at different stages of the analysis to formulate a mutual understanding of the interpretations. The interviews were conducted in a flexible manner, giving the interviewees the opportunity to elaborate on and emphasise aspects of their own choice. The extracts presented in the Results section were chosen to illuminate the different aspects brought forward in the nurses' talks. To cover the variations in their talks, we present the data extracts that convey views expressed in several interviews, as well as less common views. In the extracts, 'omitted talk' refers to comments that are not directly related to functional assessments. All names are pseudonyms

\section{Ethical considerations}

Our research plan was approved by the ethics committee of the local hospital district (reference number R16003). Written informed consent was obtained from all interviewees. Anonymity was ensured at all stages of the study. The data are stored digitally and can only be accessed by the first author. The study is reported in accordance with the consolidated criteria for reporting qualitative studies (COREQ) checklist (Tong et al., 2007). All authors agreed on the coherence and integrity of the final analysis. The principles of openness and transparency were adhered to throughout the study. 


\section{Results}

Twenty-four nurses from eight LTC facilities participated in this study. The analysis showed that care workers' views on functional assessments could not be portrayed simply as positive or negative attitudes but as discourses describing their understandings about the practicalities of care work, administrative routines, ideal care and the meaning of standard functional assessment in all these aspects. Discourses illuminate how different ways of talking portray and explain the topic at hand in a certain way, while refuting other portrayals and explanations (Wiggins \& Potter, 2017). We identified three discourses that differed in the meaning assigned to standard functional assessment in the process of care: (1) part of the bureaucracy, (2) a missed opportunity or (3) a threat to person-centred care. In the following subsections, we present the discourses and their distinctive characteristics. In their talks, the participants typically pondered different aspects of the assessments and therefore often resorted to more than one discourse while still emphasising certain aspects. We found no differences between care workers working in private and public facilities or between those working in assisted living and institutional care settings.

\section{Functional assessment as part of the bureaucracy}

The care workers often described functional assessment as a routine part of their work. Rather than a practical useful tool, they described it as an obligation dictated or directed by a third party, such as representatives of municipal or other authorities. In this kind of talk, the focus was on the instrumental and practical aspects of assessment, as reflected in the connections drawn with staff ratios, financial incentives and service fees. Additionally, the participants listed reasons for making the assessment, the people involved and the assessment schedule. 
The participants said that they were required to make the assessments at a specified frequency. Functional assessment was described as an obligatory, recurring part of their job. The position of care workers is thus reduced to a rather mechanical role in the system, simply following the instructions from the concerned authorities:

VL-N: Who, who conducts the assessment?

Elisa: Well, we do, us nurses; we make the assessment again and again. It's our job.

Typically, the assessment was portrayed as a regular part of the practical dayto-day job. The participants also discussed some of the benefits of standard assessments, describing them as beneficial to care processes, such as writing up care plans.

Almost all the care workers mentioned RAI when asked whether they assessed their residents' functioning. Both the facility's management and municipal and other authorities were described as in charge of gathering information and providing direction and regulation:

VL-N: What's your view - for whom would you say that RAl is conducted here?

Paula: Well, of course, it should be done for the resident. But sometimes, you have a sense that it's actually done for the care facility. [omitted text] It affects the care facility if... yeah, I mean they'll get more. I don't quite remember exactly how it works, but anyway, the care facility will benefit if the residents get higher scores.

Even when the regulative instance was not explicitly mentioned, it came across indirectly in the care workers' talks that regulative forces required these assessments. In these cases, the interviewees often used the pronoun 'they', referring to anonymous actors who dictated the use of and the rationale behind the assessment tools. This was commonly accepted as part of the job, but in some instances, care workers indicated that they had been given false hopes about the assessments, as described in the following extract: 
VL-N: Well, maybe about RAl, why would you say it's used here?

Olivia: It's, RAI is like, here to stay. I mean it's the most widely used [assessment] in all of Finland. [omitted text] They always tell us that if we conduct these RAl evaluations well and with care, you know, do them well and carefully, that will be reflected in like, the nursing care intensity. And erm, then like the last argument they have is that if the scores show that we have a very high work load on our ward, then we'll get more resources. And, during the time l've worked here, we've never received more [resources] based on RAl scores. And we've noticed how the caring intensity has continued to increase all the time.

In this discourse, functional assessment was described as a routine part of the job, based on rules and directives rather than residents' needs. Thus, the rationale did not stem from the logic of care work itself, but the assessments were dictated and imposed by the authorities who remained anonymous. The promise of improved efficiency and more resources remained vague and unwarranted. To summarise, in the care workers' talks, functional assessments belonged to the realm of admission rules and financial resources. They were part of the bureaucracy over which the care workers had no control.

\section{Functional assessment as a missed opportunity}

When asked, some participants pondered the rationale for functional assessments but had difficulty in finding it. In this discourse, standard functional assessments were described as potentially beneficial but poorly used practice in care work. In their talks, the care workers deliberated on whether assessments would be useful in care work and if so, in what way, as illustrated in the following excerpt:

\section{$V L-N$ : So why in your opinion is RAl used here?}

Miia: Umm. Well. I don't know whether RAl is, whether it's something that the municipal authorities actually require of us. Perhaps we [at this care facility] could use it; we do conduct RAl assessments, but perhaps it could be put to better use. They always tend to remain there for six months, on the computer. You know, they're not like, really used in the end, in the practice of care work. 
Miia's response gives an ambiguous meaning to functional assessment in care work. Similarly, even though the assessments may potentially be useful, the role of care workers and the practical benefits of the assessments remain unclear. The preceding extract is an example of how the participants tried to make sense of the assessments, pointing out that the results were not used or that they were not sure whether and how they were used. The following extract shows Joanna's attempt to answer the question of why RAI is used. Her hesitation and use of filler words like 'umm' and 'well' indicate her difficulty in giving a definitive answer:

\section{VL-N: Umm, what about RAl? Why would you say it is used here? \\ Joanna: Umm... Well, it has, like RAl is... In my opinion, it's not like, used as much as, as much as it should be, and the benefits we get, they're not really visible here in our daily [work].}

As Joanna's answer shows, in this discourse, the care workers indicated that functional assessments could be used more frequently, but their benefits in actual daily work remained invisible to the care workers who collected the information. Sometimes, they were even described as pointless, as exemplified by the following extract from Birgitta's interview:

VL-N: What would you say, who is it [the standardised assessment] conducted for?

Birgitta: Well, l've asked myself the same question. I don't know. We've been discussing this thing and you know, said, 'Let's just get them done, but no one's ever going to read them'.

As this excerpt shows, the care professionals struggled to express the meaning of functional assessment as part of their job. They did not explicitly denounce the assessment process as pointless but considered the rationale behind functional assessment. While assessment was accepted as a potentially useful tool in care, its practical effects remained invisible. Therefore, functional assessment was perceived as a missed opportunity. 


\title{
Functional assessment as a threat to person-centred care
}

In this discourse, the practice of assessing residents' functional capacity was contrasted with the recognition of residents as individuals. In this kind of talk, functional assessment was thus described as a de facto obstacle to good quality care:

\begin{abstract}
VL-N: Do you evaluate the functional capacity of patients here?
Helena: Yeah, well, I mean, we've all sorts of measurement instruments. But that sometimes feels like, I feel bad about judging someone based on their point score. That's bad, a bad way of thinking. After all, it's a human being but measured in terms of point scores. His score was low; that's pretty bad. We didn't use to do that. We appreciated people as people.
\end{abstract}

As the preceding extract illustrates, the care workers compared functional assessments with their own understandings of good care and negotiated the justification of standardised assessments. Functional assessment, described as part of their routine paperwork, was explained as a separate task that detracted from the time available for proper care work, which for the interviewees meant spending time and talking with residents. By emphasising that they perceived and approached residents as human individuals rather than scores and points, as well as by pointing out that functional assessment could never provide a full and true picture of the person, the care workers depicted the assessment tools as detrimental to good quality care work.

In this discourse, spending time with residents was portrayed as more important than conducting functional assessments:

VL-N: Umm, well, still further about RAl, what would you say, why do you use it here?

Emma: Yes, well, I'm allowed to say anything here, right [laughter]? I mean we don't, like in our daily care work, we don't use it at all. It's like, more about we do our documenting in Pegasos [digital patient information system] and in conversations, and like in our multidisciplinary team, we do this on a personal, face-to-face basis rather than going to see [the 
assessment] made by another nurse. [text omitted] You get a much better insight just by doing your own care work.

In this interview, Emma interestingly started her account with the comment that she was allowed to say anything in the interview situation. Our interpretation is that she was reminding both herself and the interviewer that the conversation was confidential, which was made clear to her at the start of the interview. Thus, her comment implied that what she was about to say was something that she would not say in some other situation. In fact, she made the point that functional assessments played no role in daily care work at all, but the residents' situations were evaluated with quite different means.

In this kind of talk, functional assessments were described as overlooking important skills and abilities of older persons and as failing to capture relevant aspects of residents' individual characteristics. In contrast to the RAI tool, the care workers depicted themselves as having the ability to understand and to bring forth residents' individual needs and preferences:

VL-N: Well, maybe about RAl, why do you think you use it here?

Olivia: [text omitted] I still think that RAI doesn't answer the questions that I think are relevant. Or I mean it does but somehow in a formal, structured way. It simplifies. Somehow, I think the results don't say anything about the individual. Nothing at all. I mean you could have a great poet there. Right here. You could have someone who could do amazing art if you'd give them a pencil. You wouldn't see that in the RAl scores.

When applying this discourse, the care workers stressed the importance of really knowing the residents and their abilities. In this context, compared with less structured and less formal ways of obtaining this knowledge, standard functional assessment was depicted as not a useful tool but an obstacle to quality person-centred care. 


\section{Discussion}

In this study, we examined LTC care workers' views on standardised functional assessments using the data collected in semi-structured interviews. The analysis was based on a discursive approach (Wiggins \& Potter, 2017), which allowed us to explore in detail the care workers' descriptions of standardised assessments as part of their daily work and the meaning that they assigned to these assessments in the context of actual care. In line with Phelan (2011), we found the discursive approach a useful tool for unravelling the taken-for-granted content of care practices, which might remain invisible in other types of analyses.

We identified three different discourses that the care workers used in constructing the meaning of functional assessments and their role in the care process. First, functional assessment was presented as part of bureaucracy and routine paperwork, relating to the means and goals of municipal authorities and the care facility's management. Second, functional assessment was described as a missed opportunity; it was a potentially useful way of supporting person-centred care, but that potential was not realised. Third, the participants contrasted care work that used standardised assessments and point scores with holistic care work that approached older people as individuals. As a result, functional assessment was even presented as a threat to person-centred care.

When asked about functional assessment, many participants mentioned RAl. Although RAI should ideally serve as a guide for understanding disabilities and the individual's functional potential (Finne-Soveri et al., 2010; Hawes et al., 1997), the care workers in our study questioned this view and noted that the assessments conflicted with the principle of recognising older persons as individuals. They reflected on the practice of functional assessment in terms of their understanding of good care, which emphasised the individual and a person-centred approach (McCormack, 2003; McCormack et al., 2012; McGilton et al., 2012). In earlier studies, nursing home personnel likewise recognised that RAI could contribute to quality of care and nursing documentation, but they expressed scepticism about the instrument's ability to give a true and full picture of an older individual (Armstrong et al., 2016; Hansebo et al., 1998; Parmelee et al., 2009). Our study's results not only support but also add to these findings. Some participants contested the idea of using scores to arrive at an assessment of the individual person. 
Conducting the assessments was described as a waste of time and pointless, stealing time that they could otherwise have spent on face-to-face interactions with residents. This is again consistent with previous studies' findings (Hansebo et al., 1998; Jogerst et al., 2002; Parmelee et al., 2009).

On a general abstract level, functional assessments were recognised as potentially useful in care work. In other words, if they were used differently, assessments could have the potential to improve care work, but none of the discourses portrayed them as belonging to the core of the practice of care or based on the needs of individual LTC residents. Rather, the participants distanced themselves from functional assessments and described them as something additional to the nurse's main duties (cf. Armstrong et al., 2016). Occasionally, they were depicted as part of routine paperwork, something that has continued to increase and expand in recent years and is threatening to reduce care workers' interaction with residents (Tainio \& Wrede, 2008; Vabø, 2006). In the nurses' view, the fundamental goals of their work are to alleviate suffering and increase the wellbeing of their patients. From this perspective, standardised assessments conflict with the logic of care. Conducting functional assessments was described as a practice dictated from the outside by municipal authorities or the care facility's management. A number of earlier studies have also drawn attention to the growth of bureaucracy and standardisation in care work (Dahl, 2009; Trydegård, 2012; Vabø, 2006) and highlighted the increase in moral stress among care workers (Kiljunen et al., 2017; O'Dwyer, 2013; Trydegård, 2012; Vabø, 2006).

Functional assessment indexes were originally developed for the purposes of predicting adverse outcomes and further decline in functioning, assessing the quality of life in older populations (Guralnik \& Lacroix, 1992), facilitating communication with others (Lawton, 1971) and assessing the outcomes of rehabilitation (Lawton, 1971; Mahoney \& Barthel, 1965). The introduction of standardised functional assessments in LTC since the early 2000s can be regarded as part of the NPM movement and its emphasis on rationalisation, quality standards and performance measures (Adcroft \& Willis, 2005; Armstrong et al., 2016). In the context of care for older people, the rationale for the use of these indexes, as explained in several policy papers and studies, is to plan care for individual recipients and survey their care needs, govern the process of care provision and allocate resources, as well as monitor the quality of care (Finlex, 2012; Finne-Soveri 
et al., 2010; Voutilainen \& Vaarama, 2005). Assessment instruments, particularly RAI, have been associated with the doctrine of evidence-based medicine, which prefers standardised evidence over anecdotal and contextual knowledge, but serious questions have been raised about the suitability of the approach to LTC (Armstrong et al., 2016).

In our study, the care workers' talks revealed the contrast between managerial goals and the ideal of good care for the individual. While the care workers largely accepted the stated purposes of standardised assessments, they did not see whether and how these purposes were met in practice. Our study was not intended to assess the relevance or usefulness of standardised assessments as such, and our findings indicate nothing about the extent to which the purposes of assessments in LTC are met. Instead, our study suggests that the rationale for these assessments, as presented in policy papers and administrative guidelines, is at odds with the experiences of LTC workers. Care workers have an unclear understanding about these assessments' role in the practice of care and question their relevance to quality care delivery. Some care workers even consider assessment a source of moral stress. These views likely have an impact on not only daily care work but also the motivation and well-being of care workers. Our findings call for a reconsideration of the role and practices of standardised functional assessments in LTC. To be a meaningful part of care, it is essential that there be a shared understanding of the rationale for measures and assessments in the care organisation and that care workers can see the practical outcomes and effects of these assessments in their daily work.

\section{Limitations}

The data for this study were gathered from both practical and registered nurses in eight LTC facilities in Finland, selected with purposive sampling. We recognise that the two groups of care workers have different educational backgrounds and partly varying responsibilities. However, both are involved in personal care for LTC residents and conduct functional assessments. We also recognise that care cultures and guidelines can vary among Finnish care facilities, and they most certainly do among different countries. Our detailed analysis reveals the variations in the meanings given to assessment tools in care work, as indicated in the interviews with care workers,and calls into question the taken-for-granted meanings of assessment tools. However, this kind of 
approach can neither show which views are the most common and which are the rarest nor establish how widely shared they are among care workers in general. Nevertheless, our sample provides useful insights into the care staff's perspectives about functional assessments and their role in care work. The results shed light on how the use of standardised instruments fits into the daily work of LTC care staff and their views on good care. Despite the relatively small sample, the themes raised and discourses identified in the interviews offer a consistent picture of staff views and perceptions.

\section{Conclusions and implications}

In this article, we have discussed care workers' views on the role and status of standardised functional assessments in LTC practices. LTC nurses described functional assessment as a routine part of their work but detached from their core duties of caregiving, even a threat to what they considered the most important part of their work. They recognised the official administrative purpose of functional assessments and their potential usefulness yet admitted their unclear understanding of whether and how the results of the assessments were used. From the care workers' point of view, the results of standardised assessments remained invisible in daily work, and in practice, these neither contributed to nor advanced good care. As far as the participants were concerned, functional assessment might have value in the nursing care for older people, but at the time of the interviews, it was not an instrument that could help achieve good care.

Standardised assessments in LTC can be understood as following the NPM doctrine that emphasises quality standards, outcomes and performance measures, even in the context of health and social care. Our findings suggest that as far as care workers are concerned, the practice of standardised assessments is at odds with the goal of good and personalised care. They draw attention to the problems of applying the NPM concept to the care for older people. The divergence between the managerial goals of functional assessments and care workers' views will likely have impacts on daily work in LTC facilities and care workers' motivation. Our findings also suggest that the results of functional assessments are not necessarily used in actual care work, contradicting the whole idea of using these tools. These findings call for a reconsideration and 
reorganisation of the role of standardised assessments to arrive at a shared understanding of their purpose.

\section{Funding}

This study was conducted in the Centre of Excellence in Research on Ageing and Care

(CoE AgeCare), funded by the Academy of Finland (project 312311).

\section{References}

Adcroft, A., \& Willis, R. (2005). The (un)intended outcome of public sector performance measurement. International Journal of Public Sector Management, 18(5), 386400. https://doi.org/10.1108/09513550510608859

Anttonen, A., \& Häikiö, L. (2011). Care 'going market': Finnish elderly-care policies in transition. Nordic Journal of Social Research, 2, 70-90. https://doi.org/10.15845/njsr.v2i0.111

Armstrong, H., Daly, T. J., \& Choiniere, J. A. (2016). Policies and practices: The case of RAI-MDS in Canadian long-term care homes. Journal of Canadian Studies, 50(2), 348-368. https://doi.org/10.3138/jcs.50.2.348

Dahl, H. M. (2009). New public management, care and struggles about recognition. Critical Social Policy, 29(4), 634-654. https://doi.org/10.1177/0261018309341903

Finlex. (2012). Act on Supporting the Functional Capacity of the Older Population and on Social and Health Care Services for Older Persons 28.12.2012/980. Retrieved December 5, 2017, from http://www.finlex.fi/fi/laki/kaannokset/2012/en20120980.pdf

Finne-Soveri, H., Hammar, T., \& Noro, A. (2010). Measuring the quality of long-term institutional care in Finland. Eurohealth, 16(2), 8-10.

Finnish National Agency for Education. (2017). Vocational qualification in social and health care. Retrieved March 19, 2020, from https://eperusteet.opintopolku.fi/\#/en/esitys/3689879/reformi/tiedot

Forma, L., Aaltonen, M., Pulkki, J., Raitanen, J., Rissanen, P., \& Jylhä, M. (2017). Long-term care is increasingly concentrated in the last years of life: A change from 2000 to 2011. European Journal of Public Health, 27(4), 665-669. https://doi.org/10.1093/eurpub/ckw260

Forma, L., Rissanen, P., Noro, A., Raitanen, J., \& Jylhä, M. (2007). Health and social service use among old people in the last 2 years of life. European Journal of Ageing, 4(3), 145-154. https://doi.org/10.1007/s10433-007-0054-4

Guralnik, J. M., \& Ferrucci, L. (2003). Assessing the building blocks of function: Utilizing measures of functional limitation. American Journal of Preventive Medicine, 25(3 Suppl 2),112-21. https://doi.org/10.1016/S07493797(03)00174-0

Guralnik, J. M., \& Lacroix, A. (1992). Assessing physical function in older populations. In R. Wallace \& R. Woolson (Eds.), The epidemiologic study of the elderly (pp. 159-179). Oxford University Press.

Hansebo, G., Kihlgren, M., Ljunggren, G., \& Winblad, B. (1998). Staff views on the Resident Assessment Instrument, RAI/MDS, in nursing homes, and the use of the Cognitive Performance Scale, CPS, in different levels of care in Stockholm, Sweden. Journal of Advanced Nursing, 28(3), 642-653. https://doi.org/10.1046/j.1365-2648.1998.00707.x

Hawes, C., Morris, J. N., Phillips, C. D., Fries, B. E., Murphy, K., \& Mor, V. (1997). Development of the nursing home Resident Assessment Instrument in the 
USA. Age and Ageing, 26(Suppl. 2), 19-25.

https://doi.org/10.1093/ageing/26.suppl_2.19

Hawes, C., Morris, J. N., Phillips, C. D., Mor, V., Fries, B. E., \& Nonemaker, S. (1995).

Reliability estimates for the minimum data set for nursing home resident assessment and care screening (MDS). Gerontologist, 35, 172-178. https://doi.org/10.1093/geront/35.2.172

Henriksson, L., \& Wrede, S. (2008). Care work in the context of a transforming welfare state. In S. Wrede, L. Henriksson, H. Host, S. Johansson, \& B. Dybbroe (Eds.), Care work in crisis: Reclaiming the Nordic ethos of care (pp. 121-130). Studentlitteratur.

Hirdes, J. P., Ljunggren, G., Morris, J. N., Frijters, D. H., Finne-Soveri, H., Gray, L., Björkgren, M., \& Gilgen, R. (2008). Reliability of the interRAl suite of assessment instruments: A 12-country study of an integrated health information system. BMC Health Services Research, 8(1), 277. https://doi.org/10.1186/1472-6963-8-277

Jogerst, G., Daly, J., \& Zimmerman, M. B. (2002). Physician use of and attitudes regarding the minimum data set. Journal of the American Medical Directors Association, 3, 40-45. https://doi.org/10.1016/S1525-8610(04)70437-5

Johansson, E. (2010). Long-term care in Finland (ENEPRI Research Report No. 76, 15 June 2010). European Network of Economic Policy Research Institutes.

Katz, S., Downs, T., Cash, H., \& Gratz, R. (1970). Progress in development of the index of ADL. Gerontologist, 10(1), 20-30. https://doi.org/10.1093/geront/10.1 Part 1.20

Kiljunen, O., Välimäki, T., Kankkunen, P., \& Partanen, P. (2017). Competence for older people nursing in care and nursing homes: An integrative review. International Journal of Older People Nursing, 12(3), 1-10. https://doi.org/10.1111/opn.12146

Lawton, M. P. (1971). The functional assessment of elderly people. Journal of the American Geriatrics Society, XIX, 465-481. https://doi.org/10.1111/j.15325415.1971.tb01206.x

Lehto, V., Jolanki, O., Valvanne, J., Seinelä, L., \& Jylhä, M. (2017). Understanding functional ability: Perspectives of nurses and older people living in long-term care. Journal of Aging Studies, 43, 15-22. https://doi.org/10.1016/j.jaging.2017.09.001

Mahoney, M., \& Barthel, D. (1965). Functional evaluation: The Barthel Index. Maryland State Medical Journal, 14, 61-65. https://doi.org/10.1037/t02366-000

McCormack, B. (2003). A conceptual framework for person-centred practice with older people. International Journal of Nursing Practice, 9(3), 202-209. https://doi.org/10.1046/j.1440-172X.2003.00423.x

McCormack, B., Roberts, T., Meyer, J., Morgan, D., \& Boscart, V. (2012). Appreciating the "person" in long-term care. International Journal of Older People Nursing, 7(4), 284-294. https://doi.org/10.1111/j.1748-3743.2012.00342.x

McGilton, K. S., Heath, H., Chu, C. H., Boström, A. M., Mueller, C., Boscart, V. M., McKenzie-Green, B., \& Bowers, B. (2012). Moving the agenda forward: A person-centred framework in long-term care. International Journal of Older People Nursing, 7(4), 303-309. https://doi.org/10.1111/opn.12010

Ministry of Social Affairs and Health. (2013). Quality recommendation to guarantee a good quality of life and improved services for older persons (Publications of the Ministry of Social Affairs and Health 2013:19).

Mor, V., Angelelli, J., Jones, R., Roy, J., Moore, T., \& Morris, J. (2003). Inter-rater reliability of nursing home quality indicators in the U.S. BMC Health Services Research, 3(20), 1-13. https://doi.org/10.1186/1472-6963-3-20/r1472-6963-3$\underline{20}$

Nilsson, M., Jönson, H., Carlstedt, E., \& Harnett, T. (2018). Nursing homes with lifestyle profiles - part of the marketisation of Swedish eldercare. International Journal of Care and Caring, 2(1), 49-64. https://doi.org/10.1332/239788218X15187914054863 
Norwegian Ministry of Health and Care Services. (2016). Dementia Plan 2020: A more dementia-friendly society. Retrieved January 23, 2020, from https://www.regjeringen.no/en/dokumenter/dementia-plan-2020/id2465117/

O'Dwyer, C. (2013). Official conceptualizations of person-centered care: Which person counts? Journal of Aging Studies, 27(3), 233-242. https://doi.org/10.1016/j.jaging.2013.03.003

Parmelee, P. A., Bowen, S. E., Ross, A., Brown, H., \& Huff, J. (2009). "Sometimes people don't fit in boxes": Attitudes toward the minimum data set among clinical leadership in VA nursing homes. Journal of the American Medical Directors Association, 10(2), 98-106. https://doi.org/10.1016/j.jamda.2008.08.004

Phelan, A. (2011). Socially constructing older people: Examining discourses which can shape nurses' understanding and practice. Journal of Advanced Nursing, 67(4), 893-903. https://doi.org/10.1111/j.1365-2648.2010.05536.x

Richards, S. H., Peters, T. J., Coast, J., Gunnell, D. J., Darlow, M. A., \& Pounsford, J. (2000). Inter-rater reliability of the Barthel ADL index: How does a researcher compare to a nurse? Clinical Rehabilitation, 14(1), 72-78. https://doi.org/10.1191/026921500667059345

Sainsbury, A., Seebass, G., Bansal, A., \& Young, J. B. (2005). Reliability of the Barthel Index when used with older people. Age and Ageing, 34(3), 228-232. https://doi.org/10.1093/ageing/afi063

Stoop, A., Lette, M., Van Gils, P. F., Nijpels, G., Baan, C. A., \& De Bruin, S. R. (2019). Comprehensive geriatric assessments in integrated care programs for older people living at home: A scoping review. Health and Social Care in the Community, 27(January), e549-e566. https://doi.org/10.1111/hsc.12793

Strandell, R. (2020). Care workers under pressure - a comparison of the work situation in Swedish home care 2005 and 2015. Health and Social Care in the Community, 28, 134-147. https://doi.org/10.1111/hsc.12848

Szebehely, M., \& Meagher, G. (2018). Nordic eldercare - weak universalism becoming weaker? Journal of European Social Policy, 28(3), 294-308. https://doi.org/10.1177/0958928717735062

Tainio, L., \& Wrede, S. (2008). Practical nurses' work role and workplace ethos in an era of austerity. In S. Wrede, L. Henriksson, H. Host, S. Johansson, \& B. Dybbroe (Eds.), Care work in crisis: Reclaiming the Nordic ethos of care (pp. 177-197). Studentlitteratur.

Tong, A., Sainsbury, P., \& Craig, J. (2007). Consolidated criteria for reporting qualitative research (COREQ): A 32- item checklist for interviews and focus group. International Journal of Qualitative in Health Care, 19(6), 349-357. https://doi.org/10.1093/intqhc/mzm042

Trydegård, G. (2012). Care work in changing welfare states: Nordic care workers' experiences. European Journal of Ageing, 9, 119-129. https://doi.org/10.1007/s10433-012-0219-7

Vabø, M. (2006). Caring for people or caring for proxy consumers? European Societies, 8(3), 403-422. https://doi.org/10.1080/14616690600821990

Voutilainen, P., \& Vaarama, M. (2005) Toimintakykymittareiden käyttö ikääntyneiden palvelutarpeen arvioinnissa [Use of measures of functional capacity in the assessment of service needs among older people] (Stakes, Reports 7/2005). The National Research and Development Centre for Welfare and Health (STAKES).

Wiggins, S., \& Potter, J. (2017). Discursive psychology. In C. Willig \& W. Rogers (Eds.), The SAGE handbook of qualitative research in psychology (pp. 93109). SAGE Publications. https://doi.org/10.4135/9781526405555.n6

Zimmerman, D. R., Karon, S. L., Arling, G., Clark, B. R., Collins, T., Ross, R., \& Sainfort, F. (1995). Development 